\title{
SUSTENTABILIDADE COMO TEMA DE PRÁTICAS PEDAGÓGICAS NA ESCOLA ESTADUAL DE EDUCAÇÃO PROFISSIONAL ALFREDO NUNES DE MELO EM ACOPIARA (CE)
}

Jones Baroni Ferreira de Menezes ${ }^{1}$

Alzeir Machado Rodrigues ${ }^{2}$

Resumo: A sustentabilidade cada vez mais vem sendo foco de diferentes áreas de conhecimento, sendo necessário trabalhar assuntos relacionados ao tema no contexto escolar. Assim, o trabalho objetivou investigar as práticas pedagógicas utilizadas no Ensino Médio sobre o desenvolvimento sustentável. Esse estudo ocorreu através da aplicação de um questionário aos alunos de $3^{\circ}$ ano da Escola Estadual de Educação Profissional Alfredo Nunes de Melo, totalizando 84 alunos. Diante do observado, a escola trabalha e tem uma atenção com relação à temática sustentabilidade $(52,38 \%)$ em sala de aula, através da metodologia de aula expositiva-dialogada, levando os alunos à conceituarem corretamente o termo sustentabilidade (73\%), porém não participam de eventos promovidos pela escola.

Palavras-chave: Ensino; Meio Ambiente; Biologia.

${ }^{1}$ Universidade Estadual do Ceará (UECE) e Faculdade de Tecnologia Intensiva (FATECI). Email: ibaroni.bio@gmail.com

${ }^{2}$ Universidade da Integração Internacional da Lusofonia AfroBrasileira (UNILAB). E-mail: alzeir.igt@gmail.com 


\section{Introdução}

As ideias de desenvolvimento e direitos humanos são duas ideias que marcaram representativamente a segunda metade do século XX. Nessas, 0 preceito das Nações Unidas assume o papel de autor e impulsionador dos artifícios de debate e construção de agendas que direcionem estes assuntos para a população (JACOBI, 2006).

Analisando sob uma perspectiva diferente, é possível observar que o discurso sobre a sustentabilidade originou-se como um substituto ao discurso que tratava do desenvolvimento econômico, produzido e propagado pelos países centrais do capitalismo, principalmente pelos Estados Unidos, e destes para o resto do mundo diante do contexto da Guerra Fria. Logo após os anos 70 do século anterior, o debate desenvolvimentista expôs seus limites por meio de uma crise, que apesar de ter uma maior visibilidade, era ao mesmo tempo social, ético-cultural e ambiental (LIMA, 2003).

O capitalismo está por toda parte, vivemos em uma sociedade que visa acima de tudo os rendimentos financeiros, porém ele encontra-se cada vez mais como um agravante para o meio ambiente, pois com o avanço nos meios tecnológicos e industriais, a exploração dos recursos está crescendo de forma preocupante (FERNANDES, 2010).

Assim, a questão ambiental entrou em voga, fazendo com que na década de 70, durante a Conferência Intergovernamental a respeito da Educação Ambiental realizada em Tbilisi (ex União-Soviética), começasse um processo, em nível global, no qual possibilitasse uma nova consciência sobre a importância do meio ambiente e para redimensionar a formação do conhecimento baseada nas formas da interdisciplinaridade e nos valores da complexidade, o convencionou-se dar o nome de Educação Ambiental (JACOBI, 2003; BRASIL, 2004).

Nesse sentido, essa nova ciência tornou-se um novo ingrediente para que proporcione uma melhor visão crítica e social nas relações entre a sociedade e o meio ambiente (LIMA, 2003), tendo, o ambiente escolar, como um lugar de formação educacional e social, que precisa trabalhar temas que sejam relevantes para a sociedade da época, pois como cidadãos e futuros profissionais do mercado de trabalho, os alunos precisam conhecer a realidade social e os fins capitalistas que a sociedade adota.

A questão ambiental é, segundo o Parâmetros Curriculares Nacional, um tema transversal, que devem ser trabalhos na escola através da interdisciplinaridade e contextualização, contribuindo significativamente no processo de sensibilização e conscientização da sociedade (BRASIL, 2000).

Tendo em vista a necessidade de trabalhar assuntos relacionados à temática sustentabilidade no contexto escolar, e tendo como pressuposto o fato da influência que as práticas pedagógicas podem ter sobre o processo de assimilação e absorção dos conhecimentos pelos alunos, vê-se a necessidade 
de uma investigação acerca das práticas pedagógicas utilizadas no Ensino Médio sobre o desenvolvimento sustentável.

\section{Metodologia}

Trata-se de uma investigação do tipo descritiva e exploratória, com uma abordagem do tipo qualitativa e quantitativa, tendo como sujeitos da pesquisa os alunos de $3^{\circ}$ ano das turmas de Enfermagem, Redes de computadores e Comércio, da Escola Estadual de Educação Profissional Alfredo Nunes de Melo localizada na cidade de Acopiara (CE), localiza-se na região Centro-Sul do Estado do Ceará, a 283 km de Fortaleza.

A Escola em questão é uma instituição de referência em educação na região, pois obtêm índices favoráveis nas avaliações externas como o SPAECE e ENEM, além de preparar os alunos para os vestibulares e para o mercado de trabalho. A escola costuma trabalhar temas que sejam relevantes para a sociedade, organizando com frequência eventos escolares.

A coleta de dados foi feita a partir da aplicação de um questionário contendo 13 questões objetivas versando sobre os aspectos conceituais, práticas pedagógicas e dificuldade de trabalhar o tema de sustentabilidade. Ele foi aplicado durante os meses de agosto e setembro de 2013 , respondido de forma anônima.

Segundo os preceitos éticos, foi utilizado o Termo de Consentimento Livre e Esclarecido (TCLE) com os sujeitos pesquisados, resguardando os mesmos de acordo com a Resolução 196/96.

\section{Resultados e discussões}

O presente estudo foi realizado com 84 alunos de $3^{0}$ ano do ensino médio da EEEP Alfredo Nunes de Melo, onde destes 52 são do sexo feminino e 32 do sexo masculino, com idade variando de 16 a 22 anos, sendo que a faixa etária predominante é de 16 a 18 anos, tendo 81 alunos nesta faixa.

\section{Ambiente Escolar e sua influência sobre a prática de sustentabilidade}

Nas indagações feitas aos entrevistados sobre como a escola (coordenação pedagógica) dá importância à temática sustentabilidade, tivemos como respostas de $52,38 \%$ dos entrevistados que a coordenação acompanha de forma constante o trabalho das disciplinas complementares, deste modo direciona as atividades relacionadas à temática sustentabilidade, o que demonstra uma preocupação da coordenação na inserção de assuntos pertinentes à realidade vivenciada pelos alunos.

Esse fato corrobora com Brasil (2007), pois o mesmo afirma que uma das principais dificuldades nos trabalhos com a educação ambiental do ponto 
de vista metodológico é a falta de práticas pedagógicas refletidas, que apresentem competências técnicas e pedagógicas, devendo estas serem acompanhadas e direcionadas pela coordenação pedagógica.

Também foi pesquisada a relação de respeito entre todos os membros da comunidade escolar (educadores, pais e alunos) e obteve-se como resposta que esta relação é positiva $(95,23 \%$ dos entrevistados), sendo marcada pelo respeito entre todos.

Segundo Brasil (2007) o respeito à diversidade e aos processos vitais são a base para o desenvolvimento de uma sociedade com princípios de cidadania e sustentabilidade. Apontando também como um dos princípios básicos para a educação ambiental 0 reconhecimento e 0 respeito à pluralidade e à diversidade individual e cultural. Tomando-se como ideia este pressuposto, surge antes da necessidade do respeito à diversidade e aos processos vitais, o respeito entre os próprios indivíduos desta sociedade, como norteador das demais relações cordiais.

Porém, Marriel et al (2006), observaram em seu estudo que a relação entre os educadores e os educandos era marcada pela falta de respeito e cordialidade, não favorecendo ao processo de formação cidadã, ponto fundamental da temática sustentabilidade.

Indagou-se também, sobre quais disciplinas trabalham o tema sustentabilidade? Os alunos apontaram como principais, respectivamente: Geografia (72,6\%), Biologia (67,8\%), Química (7,1\%), História (4,8\%), Português (4,8\%) e Matemática (1,1\%).

O fato da disciplina de Geografia ser mais citada pelos estudantes do que a disciplina de Biologia é um fator intrigante. Supõe-se que o fato da professora de Geografia ter sido a mesma durante os três anos do Ensino Médio e na disciplina de Biologia ter havido uma rotatividade de professores, seja um fator contributivo para este resultado.

Dentre todas as disciplinas, por nenhum dos indagados foram citadas as disciplinas de Física e Educação Física. De acordo com Baum e Povaluk (2012) cerca de $80 \%$ dos professores entrevistados trabalham com a educação ambiental de forma interdisciplinar, o que é preconizado pelos PCN. Porém eles retratam que os professores de Artes, Matemática e Ensino Religioso, são os que encontram maior dificuldade com o trabalho de educação ambiental. Acredita-se que isso ocorra pela falta de relação direta dessas disciplinas com as o meio ambiente em si.

Abreu e Carneiro (2009) citam vários projetos envolvendo a área da Educação Física e o desenvolvimento sustentável, de modo a retratar a importância deste trabalho de modo frequente. Dentre estes destacam-se: preservar a natureza, reciclando e brincando; reciclar, aprender e brincar: uma ação compartilhada entre família e escola; orientação na escola: um caminho 
seguro para o futuro; e unir esforços para a sustentabilidade de uma comunidade.

Da mesma forma, na Conferência Internacional sobre o Meio Ambiente e Sociedade, Educação e Consciência Pública para a Sustentabilidade, que ocorreu em Tessalônica (Grécia), foi considerado como destaque a necessidade de uma ligação entre a educação ambiental e o conceito de ética e sustentabilidade, além da efetividade dos processos de interdisciplinaridade (SORRENTINO, 1998 apud JACOBI, 2003).

Abreu e Carneiro (2009) também ressaltam a importância de todas as disciplinas trabalharem em conjunto com a temática de educação ambiental, no sentido de promover reflexões positivas e ações com relação à problemática socioambiental.

Esse trabalho em conjunto é muito importante no cotidiano escolar, pois faz com que haja uma sintonia entre todos os professores, favorecendo 0 desenvolvimento das ações propostas por toda a escola para o trabalho com a temática sustentabilidade.

No tocante de projetos educativos, de acordo com grande parte dos entrevistados (53\%), a escola poucas vezes desenvolve projetos sobre a sustentabilidade, onde seja possível haver a interação entre escola e comunidade, fazendo-o apenas em datas comemorativas específicas.

Alguns alunos afirmam que a escola nunca trabalhou com projetos envolvendo o tema sustentabilidade. Supõe-se que essa resposta se relacione ao fato desses alunos não estarem presentes nos dias em que estes projetos foram executados ou não terem interesse nesses temas, e deste modo não lembrando de suas ocorrências.

Porém, nos últimos anos, vem ganhando espaço na área educacional, uma prática pedagógica que se utilize da experimentação, simulação e participação, levando os alunos/comunidade a interagirem e exercerem suas criatividades e capacidades, o que denomina-se de Pedagogia de Projetos ou Educação por Projetos (BEAUCLAIR, 2001).

Segundo Masson et al. (2012), a aprendizagem que acontece quando os alunos se envolvem nos projetos é a aprendizagem mais desejável, pois faz com que o individuo explore e investigue seus interesses, construindo seu conhecimento e motivando-o, além de estreitar a relação com seu cotidiano, facilitando ainda mais o processo de aprendizagem.

\section{Ensino-aprendizagem do tema sustentabilidade}

No primeiro questionamento nessa temática, observamos que a maioria dos alunos entrevistados (80\%) afirma conhecer o conceito de sustentabilidade (Figura 1), sendo muito semelhante com a encontrada por 
Sarmento e Filho (2007), onde eles encontraram que $90 \%$ de sua amostra conheciam a definição de sustentabilidade.

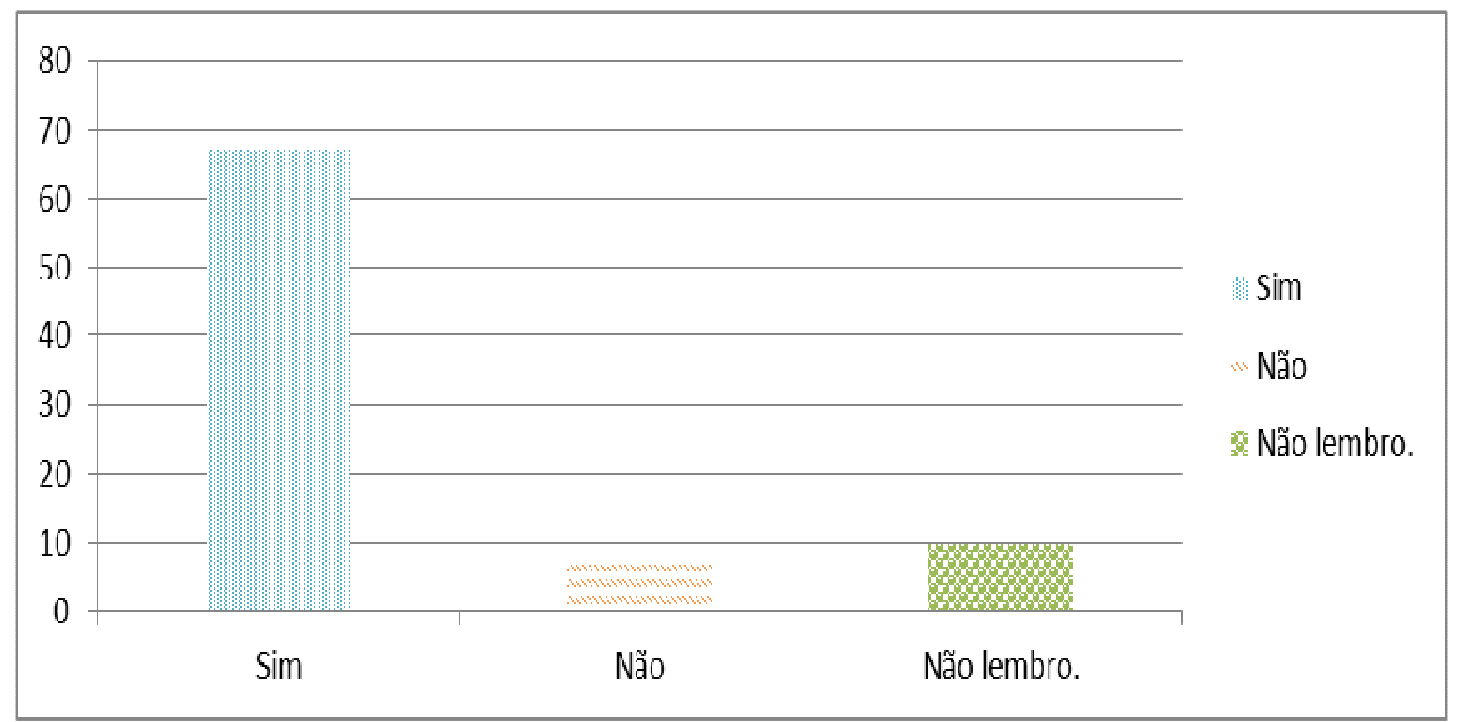

Figura 1: Conhecimento dos alunos sobre o conceito de sustentabilidade.

Fonte: Pesquisa de campo - EEEP Alfredo Nunes de Melo.

Como medida comprovatória, interrogou-os sobre a conceituação do termo sustentabilidade, tendo $73 \%$ definido de forma correta, dado que se aproxima do percentual que afirma ter conhecimento sobre o significado deste termo. Estes índices apontam para o pressuposto de que as formas de desenvolvimento dos temas associados à educação ambiental estão surtindo efeitos positivos nos educandos, já que é notória a importância desse trabalho para a formação de cidadãos críticos e preocupados com as futuras gerações.

Segundo Ataide e Silva (2011) a sociedade nos anos de 1960 e 1970 passou por grandes mudanças, e a escola como um lugar de formação para a sociedade tinha o papel de acompanhá-las. Atualmente a sociedade sofre uma série de mudanças, neste aspecto a escola e os educadores devem sempre trabalhar de modo a aperfeiçoar as metodologias de ensino, para que desta forma consigam atrair os alunos ao conhecimento. Fazer com que os jovens se sintam estimulados a estudar o meio ambiente e os impactos que a humanidade causa nele, não é uma tarefa fácil, por isso, surge à necessidade de metodologias diversificadas no ensino de sustentabilidade.

Dessa forma, foram questionadas as metodologias utilizadas para o ensino de sustentabilidade, tendo a aulas dialogadas como o método de ensino citado pela maioria dos alunos (57), onde existe a prevalência da interação professor-aluno, desta forma permitindo que o aluno interaja constantemente no decorrer da aula, apontando seus argumentos e podendo tirar suas dúvidas (Figura 2). 


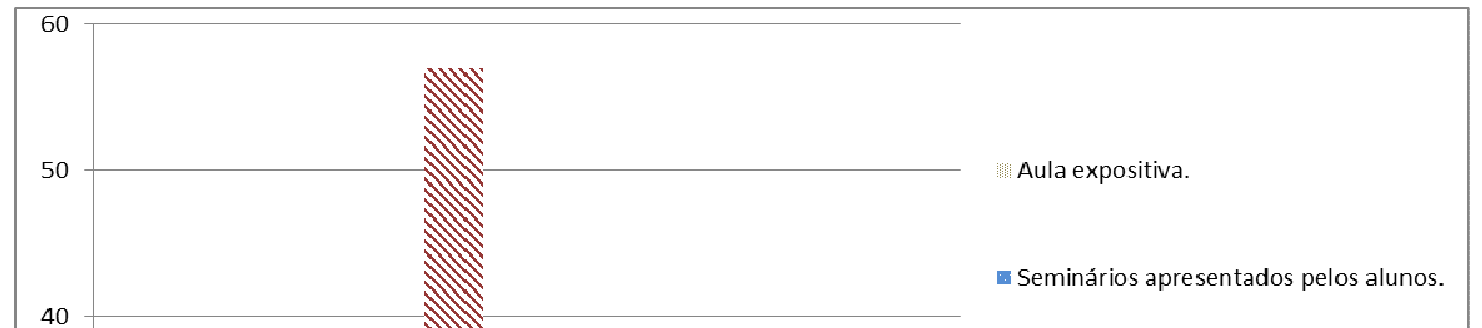

Revbea, São Paulo, V.10, № 2: 73-84, 2015. 
através das trocas de conhecimentos entre alunos e professores, de modo que se possa obter uma aprendizagem colaborativa entre todos.

As aulas expositivas dialogadas são práticas pedagógicas muito eficientes, porém no cotidiano da escola o professor deve adotar outras estratégias didáticas, de modo a facilitar o aprendizado dos alunos e motivalos. Uma dessas práticas diferenciadas são as aulas de campo.

A metodologia citada pelos alunos com menor frequência foi às aulas de campo, sendo um indicador negativo no ensino de sustentabilidade, pois DE Oliveira e Correia (2013) citam que as aulas de campo quando trabalhadas com o público de alunos de $3^{\circ}$ ano que estão vendo assuntos relacionados a ecologia e ao meio ambiente, possibilita levá-los a realidade da natureza, permite a visualização dos seres vivos em seu ambiente natural, onde é possível que eles percebam a importância que todos têm para a natureza, e deste modo se sensibilizem com questões de proteção e conservação do ambiente em que vivemos.

Um importante ponto para facilitar a aprendizagem dos alunos é a interação professor-aluno, pois é sabido que as interações sociais se fazem necessárias dentro do contexto escolar, sendo requisitos básicos para que a prática educacional tenha êxito (TASSONI, 2000).

Ao indagar se os alunos nas aulas que tratam de sustentabilidade interagem com os professores, tirando suas dúvidas e fazendo comentários relevantes ao assunto tratado, a maioria (60\%) afirmou que só fazem isso às vezes. Sendo este um dos fatores que podem dificultar o aprendizado dos alunos ao estudar o conteúdo.

Supõe-se que a interação professor-aluno na escola não seja tão otimizada por conta da quantidade de disciplinas e de conteúdos necessários para a formação do Ensino Médio Profissionalizante, visto que os alunos desta escola precisam sair com uma profissão.

De acordo com Lopes et. al. (2009) em seu trabalho sobre a interação professor-aluno, esta relação é de suma importância para que o processo de aprendizagem ocorra de modo eficiente, a autora realizou uma pesquisa onde os questionamentos eram feitos aos professores, e ao indagar sobre o diálogo e a interação dentro da sala de aula, todos os professores afirmam primar por esta relação e que a mesma ocorre de forma favorável dentro de sua sala de aula.

Porém, quando comparamos o dado observado e a metodologia mais utilizada, temos uma lacuna nesse sentido, sendo necessário que a interação esteja mais presente em sala de aula, e que ela se desenvolva de modo positivo, conservando-se o respeito mútuo, onde sejam preservados os momentos de ouvir e os de expor suas opiniões, sem constranger os educandos nem os educadores. 
Uma dessas possibilidades pode ser proporcionada através da diversificação de estratégias educacionais, se utilizando, principalmente, das que dão oportunidade dos alunos exporem, de forma mais aberta e enfática suas opiniões e ao mesmo instante ouvir opiniões que em alguns casos divergem das suas, formando deste modo um pensamento mais elaborado (ALTARUGIO, 2010).

Além da interação aluno-professor, foi perguntado sobre a presença ou não de debates crítico nas aulas associadas à temática do meio ambiente, e como resultado, obtivemos que a maioria (56\%) alega que de vez em quando acontecem debates direcionados as problemáticas atuais dos recursos naturais (Figura 3).

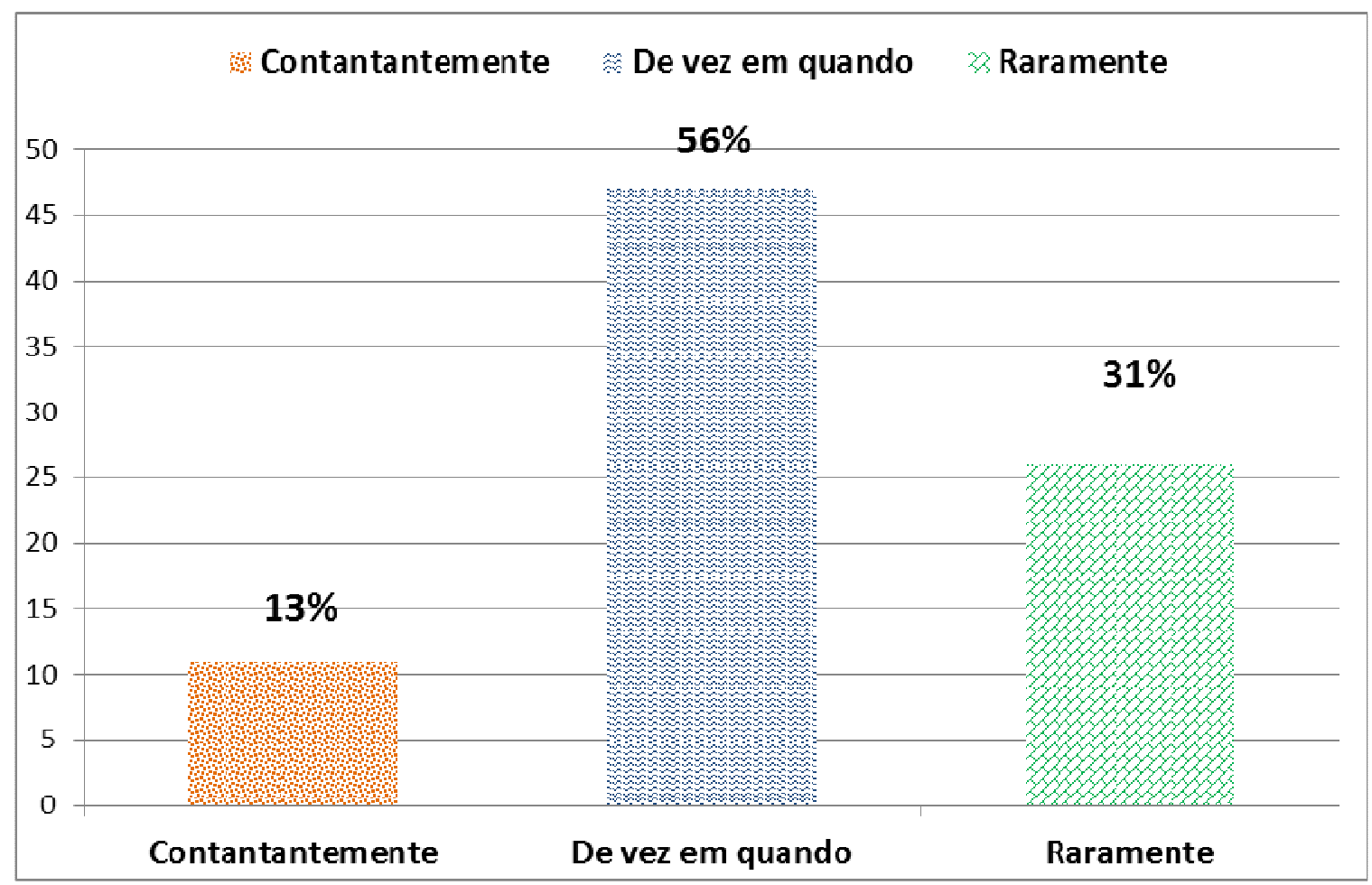

Figura 3: Presença de debates crítico nas aulas sobre o meio ambiente Fonte: Pesquisa de campo - EEEP Alfredo Nunes de Melo

De acordo com Altarugio (2010), para estimular a entrada dos alunos e envolvê-los na atividade de debate, cada professor adota estratégias distintas. Segundo a autora a ocorrência de momentos como estes proporciona aos educando uma formação crítica e reflexiva da realidade na qual o planeta terra se encontra, de modo a instigar uma consciência voltada a preservação do ambiente natural. 
Outra possibilidade de inserção e interesse do alunato é a utilização de palestras informativas, assim questionou-se a ocorrência de metodologia dessa natureza e observou-se que de acordo com a maioria dos entrevistados (69\%) a EEEP Alfredo Nunes de Melo não costuma realizar palestras sobre os recursos naturais na natureza (Figura 4).

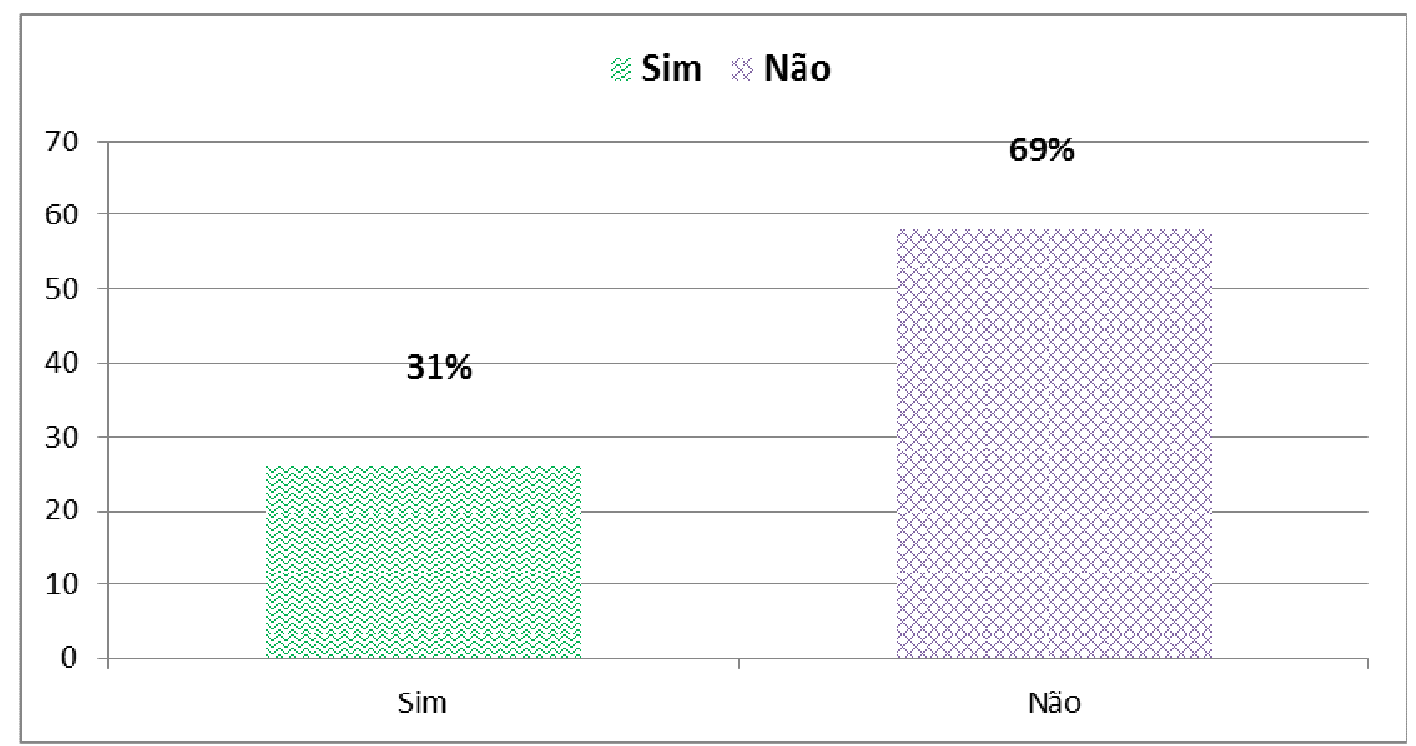

Figura 4: Ocorrência de palestras associadas aos recursos naturais disponíveis na natureza Fonte: Pesquisa de campo - EEEP Alfredo Nunes de Melo

Mas, segundo Farias e Maracajá (2012) as palestras educativas são estratégias muito eficientes na educação ambiental, e são bastante utilizadas em projetos, com 0 intuito de trabalhar assuntos relacionados ao desenvolvimento sustentável.

Esse fato corrobora com dados encontrados em nossa pesquisa, no qual $54 \%$ dos alunos da escola em estudo não se envolvem/interessam nos desenvolvidos, o que forma uma lacuna na sua formação cidadã dos mesmos.

Esses dados diferem dos obtidos por Lopes et. al. (2009) onde, em sua pesquisa, ele encontra que $66 \%$ dos alunos se engajam nos eventos escolares e demonstram uma participação ativa e contributiva.

Diante dessas questões norteadoras sobre 0 desenvolvimento sustentável é possível perceber que a instituição em estudo apresenta algumas ações pertinentes a esta temática, porém apresenta ainda algumas deficiências na forma como executar a educação ambiental. 


\section{Considerações finais}

Diante dos resultados expostos observa-se que os alunos compreendem os conhecimentos relacionados ao tema sustentabilidade, embora não se envolvam de forma intensa em projetos e eventos promovidos pela escola, que tratem da sustentabilidade.

Identificou-se nesta pesquisa que a escola desenvolve alguns trabalhos pedagógicos visando o trabalho com o tema em questão, porém não ocorre ainda de forma totalmente interdisciplinar, além de necessitar desenvolver estratégias pedagógicas que cativem os estudantes durante o processo ensinoaprendizagem, como a utilização de dinâmicas aplicadas ao ensino de sustentabilidade e não somente se utilizar das aulas expositivas-dialogadas.

\section{Referências}

ABREU, M.J.M.; CARNEIRO, S.M.M. A Relação Entre A Educação Física e a Educação Ambiental - Um Estudo na Rede Municipal de Ensino de Curitiba. In: Anais do Congresso Nacional de Educação. Outubro. 2009.

ALTARUGIO, M.H.; DINIZ, M.L.; LOCATELLI, S.W. O debate como estratégia em aulas de química. Química Nova na escola, v. 32, n. 1, p. 26-30, 2010.

ATAIDE, M.C.E.S.; CRUZ-SILVA, B.V. As metodologias de ensino de ciências: contribuições da experimentação e da história e filosofia da ciência. HOLOSISSN 1807-1600, v. 4, p. 171-181, 2011.

BAUM, M.; POVALUK, M. A educação ambiental nas escolas públicas municipais de rio negrinho, SC. Saúde Meio Ambiente.v. 1, n. 1, jun. 2012.

BEAUCLAIR, J. Educação por projetos: desafio ao edicador no novo milênio. Publicado no site www.chpesquisa.com.br, em Maio, 2001.

BRASIL, Ministério da Educação. Parâmetros Curriculares Nacionais Ensino Médio. Brasília/2000, disponível em: $<$ http://portal.mec.gov.br/seb/arquivos/pdf/blegais.pdf>, acessado em $25 \mathrm{de}$ março de 2013.

BRASIL, Ministério da Educação. Educação Ambiental: aprendizes de sustentabilidade. Brasília/2007, disponível em: $<$ http://portal.mec.gov.br/dmdocuments/publicaca02.pdf>, acessado em $01 \mathrm{de}$ janeiro de 2014.

BRASIL, Ministério do Meio Ambiente. Identidades da Educação Ambiental Brasileira. Brasília: MMA, 2004.

OLIVEIRA, C.B.E. A relação família-escola: intersecções e desafios. Estudos de Psicologia, Campinas. v. 27, no 38, Jan./Mar. 2010. Disponível em: $<$ http://www.scielo.br/scielo.php?pid=S0103166X2010000100012\&script=sci arttex t\&gt;>. Acesso em: 05 nov. 2013. 
FARIAS, M.F.; MARACAJÁ, K.F.B. Projeto de educação ambiental em escolas na cidade de Currais Novos (Rio Grande do Norte, Brasil) como facilitador na relação da educação ambiental e o turismo. Turismo e Sociedade, v. 5, n. 1, 2012.

FERNANDES, C. O capitalismo e o Advento de uma sociedade de consumo. Colégio Mãe de Deus. V. 1 № 1, 2010.

JACOBI, P. Educação Ambiental e o Desafio da Sustentabilidade Socioambiental. Mundo da Saúde- vol30/4- Centro Universitário São CamiloSP, 2006.

LIMA, G.C. O Discurso da sustentabilidade e suas implicações para a educação. Ambiente \& Sociedade - Vol. VI n‥ 2, 2003.

LOPES, R.C.S. A relação professor aluno eo processo ensino aprendizagem. Paraná: 2009.

MARRIEL, L.C. et al. Violência escolar e auto-estima de adolescentes. Cadernos de pesquisa, v. 36, n. 127, p. 35-50, 2006.

MASSON, T.J.; MIRANDA, L.F.; MUNHOZ JR, A.H.; CASTANHEIRA, A.M.P. Metodologia de Ensino: aprendizagem baseada em projetos. Anais do XL Congresso Brasileiro de Educação em Engenharia. 2012.

MORAIS, M.F. A utilização de métodos participativos no ensino de engenharia de produção: o caso do curso de engenharia de produção agroindustrial da FECILCAM. Anais do Encontro de produção científica e tecnológica. Disponível em: <http://www.fecilcam.br/nupem/anais iv epct/PDF/engenharias/04 MORAIS.pd $\mathrm{f}>$, acessado em 26 de janeiro de 2013.

SARMENTO, B.R.; FILHO, J.N.R. Análise do conhecimento acerca da sustentabilidade ambiental no Curso Superior de Tecnologia em Design de Interiores do CEFET-PB. Anais do II Congresso de pesquisa e inovação da rede norte nordeste de educação tecnológica. João Pessoa - PB.

TASSONI, E.C.M. Afetividade e aprendizagem: a relação professor-aluno. Anais da Reunião anual da ANPED, v. 23, 2000. 